\title{
TECHNOLOGY DEVELOPMENT FOR IRON FISCHER-TROPSCH CATALYSIS
}

$$
\begin{aligned}
& \text { DOE/PC/94055-T T6 } \\
& \text { M96050300 }
\end{aligned}
$$

Contract No. DE-AC22-91PC94055

Quarterly Technical Progress Report No. 6

Covering the Period January 1, 1996 to March 31, 1996

Prepared for

U.S. Department of Energy

Pittsburgh Energy Technology Center

PETC Project Manager: Richard E. Tischer

P. O. Box 10940

Pittsburgh, PA 15236-0940
Submitted by

Project Manager: Burtron H. Davis

University of Kentucky Research Foundation

Kinkead Hall

Lexington, KY 40506-0057

Revised and Accepted

$$
\text { May 1, } 1996
$$

2503103

OSTI 


\section{DISCLAIMER}

Portions of this document may be illegible in electronic image products. Images are produced from the best available original document. 


\section{DISCLAIMER}

This report was prepared as an account of work sponsored by an agency of the United States Government. Neither the United States Government nor any agency thereof, nor any of their employees, makes any warranty, express or implied, or assumes any legal liability or responsibility for the accuracy, completeness, or usefulness of any information, apparatus, product, or process disclosed, or represents that its use would not infringe privately owned rights. Reference herein to any specific commercial product, process, or service by trade name, trademark, manufacturer, or otherwise does not necessarily constitute or imply its endorsement, recommendation, or favoring by the United States Government or any agency thereof. The views and opinions of authors expressed herein do not necessarily state or reflect those of the United States Government or any agency thereof. 


\section{Contract Objectives}

The objective of this research project is to develop the technology for the production of physically robust iron-based Fischer-Tropsch catalysts that have suitable activity, selectivity and stability to be used in the slurry phase synthesis reactor development. The catalysts that are developed shall be suitable for testing in the Advanced Fuels Development Facility at LaPorte, Texas, to produce either low- or high-alpha product distributions. Previous work by the offeror has produced a catalyst formulation that is 1.5 times as active as the "standard-catalyst" developed by German workers for slurry phase synthesis. The proposed work will optimize the catalyst composition and pretreatment operation for this low-alpha catalyst. In parallel, work will be conducted to design a high-alpha iron catalyst this is suitable for slurry phase synthesis. Studies will be conducted to define the chemical phases present at various stages of the pretreatment and synthesis stages and to define the course of these changes. The oxidation/reduction cycles that are anticipated to occur in large, commercial reactors will be studied at the laboratory scale. Catalyst performance will be determined for catalysts synthesized in this program for activity, selectivity and aging characteristics.

The research is divided into four major topical areas: (a) catalyst preparation and characterization, (b) product characterization, (c) reactor operations, and (d) data assessment.

To accomplish the objectives of the project, these topics have been organized into the following technical tasks:

a. Task 1.0 Development of Optimum Promoter Levels for Low- and High-Alpha Catalysts 
1.1 Determine Optimized Synthesis Procedure for High-Alpha IronBased Fischer-Tropsch Catalysts

- Role of precursor particle size on activity.

- Role of $\mathrm{Cu}$ in precipitated catalysts.

- Define attrition resistance.

1.2 Prepare Catalysts that can be Used to Determine the Role of Promoters for Low- and High-Alpha Catalysts

- Define optimum $\mathrm{SiO}_{2}$.

- Define optimum $\mathrm{Al}_{2} \mathrm{O}_{3}$.

1.3 Prepare Catalysts that can be Used to Quantify the Role of K on Product Selectivity in both Low- and High-Alpha Catalysts.

1.4 Complete the Optimization of the Two Best Low-Alpha, Iron-Based Fischer-Tropsch Catalysts Developed during the Previous Contract.

b. Task 2.0 Definition of Preferred Pretreatment for both Low- and High-Alpha Fischer-Tropsch Catalysts.

2.1 Determine the Role of $\mathrm{Cu}$ in the Activation of Precipitated Lowand High-Alpha, Iron-Based Fischer-Tropsch Catalysts.

2.2 Determine the Effect of $\mathrm{K}$ Content on Activation Procedures and Determine if the Method of Addition has any Effect on Catalyst Activity and Life.

2.3 Determine the Physical and Chemical Changes that Occur during Catalyst Pretreatment and Use and Determine how these Changes Effect the Strength of the Catalysts. 
2.4 Evaluate the Effect of Carbon Deposition during Catalyst Activation on Activity, Selectivity and Aging Characteristics.
c. Task 3.0 Catalyst Structure and Characterization.
d. Task 4.0 Catalyst Testing.

4.1 Verify the Quality of Data Obtained from the CSTR's.

4.2 Measure Catalyst Performance.

4.3 Determine the Stable Phases that Exist during Synthesis at Low and High CO Conversion Levels.

4.4 Obtain Data on the Rates Involved in the Interconversion of Iron Oxide and Iron Carbide.

\section{e. Task 5.0 Reports.}

\section{Summary of Activities}

The water soluble $\mathrm{C}_{1}-\mathrm{C}_{4}$-oxygenates are formed in significant quantities during the Fischer-Tropsch synthesis. Thus, this water soluble oxygenate fraction represents about $1.5-2 \mathrm{wt} . \%$ of the hydrocarbon/oxygenate products; the alumina containing catalyst produces about $0.5 \mathrm{wt} . \%$ more oxygenates than the silica containing catalyst with a similar potassium content. In general, as the catalyst ages, the amount of oxygenates produced per unit of syngas converted gradually increases. The oxygenates production in general mirrors that of the $\mathrm{CO}$ conversion; that is, the higher the conversion the lower the oxygenates production.

The distribution of the compounds within the oxygenates is primarily determined by the amount of potassium in the catalyst but is essentially independent of the alumina or silica content. Thus, for a given alkali loading, the carbon number 
distribution of the catalyst is independent of the amount of either alumina or silica in the catalyst in the 4 to 8 wt.\% loading.

As the alkali loading of the catalyst is increased the normal alcohol fractions decrease. The oxygenate that increases most dramatically with an increase in potassium loading is the aldehyde class of compounds. The increase in ethanal is much less, relative to ethanol, than the increase in propanal relative to 1-propanol. At least some fraction of the ethanal is converted to products consistent with aldol condensation reactions to produce higher carbon number compounds that are not soluble in the aqueous phase. The ethanol-ethanal is essentially in equilibrium during synthesis using a C-73 catalyst manufactured by United Catalyst, Inc. (L.-M. Tau, H. A. Dabbagh and B. H. Dabbagh, Energy \& Fuels, 5 (1991) 174); thus, the same ethanol/ethanal ratio was obtained whether ethanol or ethanal was added to the syngas feed. This was not the case in the present study. For the catalyst containing 3 to $5 \mathrm{wt} . \%$ potassium, the propanal/1-propanol ratio was about 4 whereas for the catalyst with 0.5 wt.\% potassium this ratio was 0.1 or less. This observation implies that for the high loadings of potassium, the inability of the catalyst to establish this equilibrium is due to the enhancement of the desorption of the aldehyde and/or $\mathrm{CO}$ inhibition retards readsorption of the aldehyde. Furthermore, at least for the high potassium loadings, the formation of the high concentration of aldehyde implies that the aldehyde, and not the primary normal alcohol, is a primary product of the FischerTropsch synthesis. It seems likely that the direct formation of the aldehyde occurs by a reaction pathway that competes with the Fischer-Tropsch synthesis and which is similar to or is a hydrocarbonylation reaction. 
In summary, it appears that a Fischer-Tropsch plant that has the objective of developing a chemicals component based upon oxygenates would want to use alumina as the structural promoter. Furthermore, the operator could have some control over the amount and distribution of the oxygenate products by controlling the level of potassium that is present in the catalyst.

\section{Status, Accomplishments, Results and Discussion}

\section{A.0. - Task 1.0. Development of Optimum Promoter Levels for Low- and High-}

\section{Alpha Catalysts}

The goal of this task is to identify and optimize procedure for the preparation of iron-based catalysts that combine high activity selectivity and life with physical robustness. Each of the subtasks address an area of considerable uncertainty in the synthesis of catalysts.

\section{A.1. Determine Optimized Synthesis Procedure for High-Alpha Iron-Based}

\section{Catalysts}

We have developed a supported catalyst $\left(\mathrm{Fe} / \mathrm{Cu} / \mathrm{K}\right.$ on $\left.\mathrm{Al}_{2} \mathrm{O}_{3}\right)$ which has the required robustness for use in a CSTR. The testing of this catalyst is still going after 700 hours on stream. The results obtained to date verify our earlier work with respect to activity and is producing approximately $50 \mathrm{~g}$ hydrocarbon per day from the reactor. The run is being performed at $230^{\circ} \mathrm{C}$ and a $30 \mathrm{wt} . \%$ catalyst loading $(10 \mathrm{wt} . \% \mathrm{Fe})$ and is having no problems with the catalyst/wax separation. The CO conversion is running at approximately $65 \%$ and has a production rate of approximately $0.4 \mathrm{~g}$ hydrocarbon/(day)(g-Fe). The methane and ethane selectivity for this catalyst composition is low and the selectivity to olefins is high for carbon numbers up to $C_{20}$. Work is continuing to optimize the catalyst composition. Even though the catalyst has 
not been optimized, the catalyst has an activity and production rate that would make it commercially attractive.

\section{A.2. Prepare Catalysts that can be Used to Determine the Role of Promoters}

\section{for Low- and High-Alpha Catalysts}

The mechanism of the Fischer-Tropsch Synthesis (FTS) has elicited an ongoing debate since its discovery in the 1920s. Initially it was viewed that a bulk carbide formed and was then hydrogenated to produce hydrocarbons. During the 1950 s the oxygenate intermediate received wide acceptance, primarily due to the ${ }^{14} \mathrm{C}$ tracer studies of Emmett and his coworkers (Blyholder, G. and Emmett, P. H., J. Phys. Chem., 64 (1960) 470 and references therein). Subsequently, the results from surface science studies led to the revival of the carbide intermediate, but one that involved only the formation of a surface carbide.

The production of methanol from syngas should follow a simpler mechanism than the FTS and, at the same time, provide some insight into the FTS mechanism. However, even the mechanism for the methanol synthesis is complex and involves controversy. Klier and co-workers (Klier, K., Advan. Catal., 31 (1982) 243) advanced the view that methanol is synthesized from the CO component of the reactant mixture and that $\mathrm{CO}_{2}$ served to maintain the catalyst in a partially oxidized state. On the other hand, other workers have claimed that methanol is formed directly from $\mathrm{CO}_{2}$ and not from CO (Bowker, M., Hyland, J. N. K., Vandervell, H.D., and Waugh, K. C., Proc. 8th Int. Congr. Catal., 1984, Vol. II, p. 35; Bowker, M., Hadden, R. A., Houghton, H., Hyland, J. N. K., and Waugh, K.C., J. Catal., 109 (1988) 263). It appears that the contribution of $\mathrm{CO}$ and $\mathrm{CO}_{2}$ to the synthesis of methanol depends upon the process 
conditions, and especially the partial pressures. While there are many differences between the FTS and methanol synthesis, they do have the commonality of having both $\mathrm{CO}$ and $\mathrm{CO}_{2}$ present in either the reactant feed or during the synthesis due to the activity of the iron-based catalysts for the water-gas-shift (WGS) reaction.

The present work was initiated as an effort to assess the contribution of the WGS to the Fischer-Tropsch reaction since it was conceivable that $\mathrm{CO}_{2}$ could be formed by a mechanism involving the two reaction steps shown below:

$$
\begin{gathered}
\mathrm{CO} \rightarrow \mathrm{C}_{\mathrm{ads}}+\mathrm{O}_{\mathrm{ads}} \\
\mathrm{O}_{\mathrm{ads}}+\mathrm{CO}_{\text {ads or gas }} \rightarrow \mathrm{CO}_{2}
\end{gathered}
$$

Thus, the products from a combination of reactions [1] and [2] would be the same as if the WGS had operated. On the other hand, if the WGS reaction was rapid compared to the FTS we would expect ${ }^{14} \mathrm{C}$, added in the $\mathrm{CO}_{2}$, to rapidly redistribute and to be present in the CO. Surprisingly, when this experiment was performed, we found that the radioisotope distribution was such that it indicated that chain initiation could occur from an intermediate derived from $\mathrm{CO}_{2}$ but that chain growth occurred using carbon derived only from CO (Xu, L., Bao, S., Tau, L.-M., Chawla, B., and Dabbagh, H., "11th Ann. Int. Pittsburgh Coal Conf. Proc.", 1994, p 88). Furthermore, of the $\mathrm{CO}_{2}$ that was converted, half, or more than half, was converted to hydrocarbons (Xu, L., Bao, S., Tau, L.-M., Chawla, B., and Dabbagh, H., "11th Ann. Int. Pittsburgh Coal Conf. Proc.", 1994, p 88).

In view of the incorporation of $\mathrm{CO}_{2}$ as well as $\mathrm{CO}$ and this similarity to the methanol synthesis, it was of interest to re-examine the formation of oxygenates and their dependence upon the promoter level. Thus, we have compared the amounts of 
oxygenates in the aqueous phase product fraction from catalysts with various levels of potassium promoter and with either alumina or silica as the added structural promoter. While some oxygenates, and especially the higher carbon number compounds, will be in the hydrocarbon layer, the amount of oxygenates present in the aqueous phase should be related to the total amount of oxygenates formed. In addition, the oxygenates present in the aqueous phase are more easily recovered for potential use as chemicals than those that are present in the hydrocarbon fractions.

The run to determine the incorporation of $\mathrm{CO}_{2}$ was conducted in a 1-liter CSTR system (Xu, L., Bao, S., Tau, L.-M., Chawla, B., and Dabbagh, H., "11th Ann. Int. Pittsburgh Coal Conf. Proc.", 1994, p 88) using a catalyst containing $4.4 \mathrm{Si}$ and $0.71 \mathrm{~K}$ (based on $\mathrm{Fe}=100)$. The catalyst was pretreated with syngas $\left(\mathrm{H}_{2} / \mathrm{CO}=0.7\right)$ for 24 hr. at $270^{\circ} \mathrm{C}$ and $1 \mathrm{~atm}$ absolute. The synthesis was effected at $175 \mathrm{psig}$ and $270^{\circ} \mathrm{C}$ with the molar gas compositions $\left(\mathrm{H}_{2} / \mathrm{CO} / \mathrm{CO}_{2}\right)$ and flows as follow: 0 to $480 \mathrm{hr}$. (50/25/25), $3.4 \mathrm{NL} / \mathrm{hr}-\mathrm{g} . \mathrm{Fe} ; 504$ to $720 \mathrm{hr}$. (66/0/34), $2.54 \mathrm{NL} / \mathrm{hr}-\mathrm{g} . \mathrm{Fe} ; 744$ to $1200 \mathrm{hr}$. (60/10/30), 2.83 NL/hr-g.Fe. Starting at hour 1,032 and continuing for $72 \mathrm{hr} .,{ }^{14} \mathrm{CO}_{2}$ was added as a component of the feed gas. The ${ }^{14} \mathrm{CO}_{2}$ was added with the unlabeled $\mathrm{CO}\left(0.22\right.$ mole $\left.\%{ }^{14} \mathrm{CO}_{2}\right)$. The hydrogen, $\mathrm{CO}$ and $\mathrm{CO}_{2}$ streams feed to a mixing tank where the gases could be completely mixed prior to entering the CSTR. The analyses for the products have been described $(\mathrm{Xu}, \mathrm{L}$., Bao, S., Tau, L.-M., Chawla, B., and Dabbagh, H., "11th Ann. Int. Pittsburgh Coal Conf. Proc.", 1994, p 88). The runs to define the production of oxygenates were conducted as described above but without $\mathrm{CO}_{2}$ added to the synthesis gas. The catalysts were prepared by precipitation at a pH of 8.5-9.5 by feeding the required amounts of streams of 
concentrated ammonium hydroxide and iron nitrate plus either aluminum nitrate or dispersed silica obtained by hydrolysis of tetra-butoxy silicon to a CSTR where the residence time was about 6 min. The precipitate was washed two times with distilled water by repeated filtration/redispersion cycles. After the solid was dried at $110^{\circ} \mathrm{C}$ for about three days, the required amount of a potassium nitrate solution was added by the incipient wetness technique to produce the desired amount of potassium in the final catalyst. The catalyst was pretreated with $\mathrm{CO}$ as described above or with syngas at $1 \mathrm{~atm}$. for 24 hours at $270^{\circ} \mathrm{C}$ prior to the synthesis runs. The reaction conditions were those utilized in the above example for a flow of synthesis gas of $3.4 \mathrm{NL} / \mathrm{hr}-\mathrm{g} . \mathrm{Fe}$; the temperature used to effect the synthesis was 270 or $230^{\circ} \mathrm{C}$. The aqueous phase was collected separately and the content of alcohols was measured using g.c. with a Porpack column. The synthesis with these catalysts at the conditions employed will produce $208 \mathrm{~g}$ hydrocarbons and oxygenates $/ \mathrm{m}^{3}$ synthesis gas converted. The total oxygenates are based upon this yield of liquid and gaseous hydrocarbon plus oxygenate products.

$\mathrm{CO}_{2}$ Incorporation Run

The conversion data during the run to determine the incorporation of $\mathrm{CO}_{2}$ are illustrated in figure 1. During the period when equal molar amounts of $\mathrm{CO}$ and $\mathrm{CO}_{2}$ were added ( 0 to $480 \mathrm{hr}$.), a portion of the $\mathrm{CO}$ was converted to $\mathrm{CO}_{2}$ and the $\mathrm{CO}_{2}$ conversion therefore appears to be negative. During the period when only $\mathrm{H}_{2}$ and $\mathrm{CO}_{2}$ were fed (504 to $720 \mathrm{hr}$.), the $\mathrm{CO}_{2}$ conversion was about $25 \%$. The conversion of $\mathrm{CO}_{2}$ decreased when the amount of $\mathrm{CO}$ was increased during the third period of the run and, as expected, the lower partial pressure of $\mathrm{CO}$ led to a lower percentage conversion of $\mathrm{CO}$. 
During the period of ${ }^{14} \mathrm{CO}_{2}$ addition the conversion of $\mathrm{H}_{2}$ was about $32 \%$, of $\mathrm{CO}$ about $74 \%$ and of $\mathrm{CO}_{2}$ about $9 \%$. During this period $\mathrm{CO}_{2}$ was converted to $\mathrm{CO}$ so that these two gases exiting the reactor had essentially the same radioactivity/mole $\left(1.7 \times 10^{2}\right.$ for $\mathrm{CO}$ and $1.3 \times 10^{2}$ for $\left.\mathrm{CO}_{2}\right)$. Thus there was certainly interchange between these two compounds toward a similar specific radioisotope label.

The analysis of the $\mathrm{C}_{4}-\mathrm{C}_{10}$ hydrocarbons indicates that all hydrocarbons have radioactivity (figure 2). This is a not a surprising result. A similar result was obtained when the ${ }^{14} \mathrm{CO}_{2}$ was added as a tracer but at a low chemical composition $(0.2$ mole\% of the $\mathrm{CO}$ ). The result that was obtained with low concentration of $\mathrm{CO}_{2}$ is the one expected when the ${ }^{14} \mathrm{CO}_{2}$ serves to initiate but that the chain growth is due to the unlabeled $\mathrm{CO}$. The surprising result is the shape of the curve in figure 2 .

If there was significant WGS conversion and it occurred at a rate that was similar to or exceeded that of the hydrocarbon synthesis, one would expect the $\mathrm{CO}$ to contain significant ${ }^{14} \mathrm{C}$ as well as the $\mathrm{CO}_{2}$. If the $\mathrm{CO}$ and $\mathrm{CO}_{2}$ served to initiate chain growth and the $\mathrm{CO}$ to cause chain growth, the radioactivity/mole should increase with carbon number. Furthermore, the slope of the line should be equal to the ${ }^{14} \mathrm{C}$ content of the CO. Thus, if the WGS reaction had attained equilibrium prior to the beginning of the FTS, the radioactivity of $\mathrm{C}_{1}$ should be the same as that of the $\mathrm{CO}_{2}$ (and, in this case, the same as $\mathrm{CO}$ ) that initiates the reaction and the slope of the line defining the radioactivity/mole versus the carbon number should have had a slope that is defined by the radioactivity of the $\mathrm{CO}$. This is exactly the result that is obtained for the hydrocarbons in the carbon number range $C_{1}$ to $C_{4}$ but the trend does not apply for carbon numbers higher than 4 . 
One of the puzzling features of the earlier tracer studies was the result that the low isotopic distribution for the lower carbon number compounds was consistent with chain initiation by either an added alcohol or alkene; however, the $\mathrm{C}^{14} / \mathrm{mole}$ for the higher carbon number compounds decreased with increasing carbon number (figure 3). The slope of the line for the higher carbon number compounds for many runs that utilized different alcohols and alkenes were in the range of -0.06 to -0.24 and appeared to depend upon the operating conditions (Davis, B. H., "Mechanism of Promotion of Fischer-Tropsch Catalysts", DOE/PC/70029-T1, Final Report, December 1987). Originally the reason advanced for the decrease in the radioactivity/mole for the higher hydrocarbons was that two independent FTS chains contributed to the FTS reaction mechanism. However, more recent work indicates that the accumulation of hydrocarbons may also impact the ASF plot and even give the appearance of a twoalpha mechanism (Raje, A. and Davis, B. H., submitted).

The slope of the line, based on the log (radioactivity/mole) as was done in figure 3 , is -0.06 , in agreement with the lower values obtained earlier. Thus, it appears that the accumulation of hydrocarbons in the CSTR prior to the addition of the ${ }^{14} \mathrm{CO}_{2}$ dilutes the products in the $\mathrm{C}_{4}-\mathrm{C}_{9}$ hydrocarbon range sufficiently to cause the apparent decline in the radioactivity/mole.

The present data together with our earlier data are consistent with the high partial pressure of $\mathrm{CO}$ inhibiting the adsorption of $\mathrm{CO}_{2}$ and this, combined with the low $\mathrm{H}_{2} / \mathrm{CO}$ ratio, caused $\mathrm{CO}_{2}$ to only initiate chain growth. However, the lower $\mathrm{CO}$ partial pressure in the present study together with the higher $\mathrm{H}_{2} / \mathrm{CO}$ ratio caused significant WGS to occur. Thus, the synthesis was conducted with the added ${ }^{14} \mathrm{C}$ about equally distributed between the $\mathrm{CO}$ and the $\mathrm{CO}_{2}$, and this caused a linear 
increase in the radioactivity/mole for the $\mathrm{C}_{1}-\mathrm{C}_{4}$ hydrocarbons, as seen in figure 2 . The accumulation of unlabeled hydrocarbons causes the radioactivity to be diluted for the higher carbon number hydrocarbons and the observed decline in the radioactivity/mole versus carbon number plot.

\section{Oxygenate Production Runs}

The amount of oxygenates that are present in the aqueous layer depends upon the level of alkali in the catalyst (figure 4). In general, the alumina containing catalysts produce as much or more oxygenates than the silica containing catalyst. This is a surprising observation since alumina is known to be a much more active catalyst for the dehydration of alcohols than silica is. For an iron ammonia synthesis catalyst, it is generally accepted that the aluminum is present predominantly, or completely, as islands of alumina that cover a significant fraction of the iron surface (V. Solbakken, A. Solbakken and P. H. Emmett, J. Catal., 15 (1969) 90). Thus, if the aluminum in the Fischer-Tropsch catalysts was present as alumina islands on the surface, it is anticipated that it should function as an alcohol dehydration catalyst (B. H. Davis, J. Org. Chem., 37 (1972) 1240; B. H. Davis, J. Catalysis, 26 (1972) 348; D. J. Collins, R. Miranda and B. H. Davis, J. Catal., 88 (1984) 542). However, the experimental data differ from this expectation. This implies that the aluminium is present in FischerTropsch catalysts in a form that differs from that of three-dimensional islands of alumina supported on the iron/iron oxide/iron carbide catalyst surface.

For the catalyst that contains 4.4 atomic ratio of $\mathrm{Al}$, there is a dramatic increase in the amount of oxygenates that are formed as small amounts of potassium are incorporated into the catalyst; however, increasing the potassium content above about 
0.5 wt.\% produces only a slight, if any, increase in the amount of oxygenates that are formed. For a given potassium content in the alumina containing catalyst, it appears that about $0.5 \mathrm{wt} . \%$ more oxygenates are produced at $230^{\circ} \mathrm{C}$ than at $270^{\circ} \mathrm{C}$.

For the same potassium content, the catalyst containing silica produces about half as much oxygenates at $270^{\circ} \mathrm{C}$ as the alumina containing catalyst at the same reaction conditions (figure 4). At $230^{\circ} \mathrm{C}$ the oxygenate production for the silica containing catalyst presents a different dependence on potassium content than for the alumina containing catalyst. Thus, the maximum oxygenates are obtained for the catalyst containing $0.5 \mathrm{wt}$ \% potassium, and the amount of oxygenates decline to a low value as the potassium loading is increased beyond $0.5 \mathrm{wt} . \%$.

The CO conversions for the runs that produced the data shown in figure 4 are indicated in figure 5. For the alumina containing catalyst the shape of the CO conversion curves resemble in general those of the oxygenates production that were obtained at the same reaction temperature. The data for the alumina containing catalyst without alkali were obtained at an earlier reaction time that for the other catalysts and may therefore be somewhat higher than it would have been obtained at later times on stream. For the particular silica containing catalysts utilized for generating the data shown in figures 4 and 5 at $270^{\circ} \mathrm{C}$, the $\mathrm{CO}$ conversion pattern is just opposite that of the oxygenates production curve. These silica containing catalysts are not the ones that produce the optimum CO conversion, and the results for the high activity silica containing catalysts are discussed below. For the silica catalysts, the maximum $\mathrm{CO}$ conversion at $230^{\circ} \mathrm{C}$ is obtained for a catalyst that contains about 3 wt.\% potassium; the shape of the curve shown in figure 5 for the silica containing catalyst has been verified by repeat runs at $230^{\circ} \mathrm{C}$. Again, it is noted 
that the $\mathrm{CO}$ conversion/potassium content curve is essentially the mirror image of the oxygenates production/potassium content curve.

The relative amount of oxygenates usually increase as the catalyst remains on stream. This is illustrated by the data in figure 6 , and indicates that the amount of each oxygenate formed increases as the catalyst ages to provide a gradual decrease in $\mathrm{CO}$ conversion.

In general, the water-gas-shift reaction occurs to a greater extent with the alumina containing catalyst than with the silica containing catalyst. This, combined with the higher production of oxygenates with the alumina containing catalyst, causes the weight percent of oxygenates to be much higher in the water fraction for the alumina containing catalyst (figures 6 and 7 ).

The amount of potassium in the catalyst impacts the oxygenate distribution as well as the total amount of oxygenates formed. Thus, for the silica containing catalyst, the amount of methanol declines continuously from about $30 \%$ to less than $10 \%$ as the potassium level is increased from 0 to $5 \mathrm{wt. \%}$ (figure 8). As the potassium loading is increased the amount of ethanol (and ethanal) and propanol (and propanal) increased up to a loading of about $1 \mathrm{wt.} \%$ potassium and then declines with further increases in potassium content. The dominant change in the oxygenate composition in going from 1 to $3 \mathrm{wt} \%$ potassium is the dramatic increase in the amount of propanal that is formed. Whereas the propanal concentration dramatically increased to become the dominant oxygenate in the aqueous phase for the $3 \mathrm{wt} . \%$ potassium catalyst, the amount of ethanal (acetaldehyde) did not increase significantly. A partial explanation for this is that the ethanal undergoes condensation reactions to produce higher carbon number components that have been identified as components in the oil 
fraction (A. W. Fort, D. J. Houpt and B. H. Davis, unpublished results). The oxygenates distribution for the alumina ( 4.4 atomic fraction) containing catalyst was very similar to that shown in figure 9 for the silica catalyst except that the maximum for the fraction represented by ethanol and 1-propanol was attained at about $0.5 \mathrm{wt} . \%$ alkali, a lower basic promoter level than was needed to obtain the maximum for the silica containing catalyst. The dependence of the oxygenates distribution, as well as the maximum for ethanol and 1-propanol, was essentially the same at $230^{\circ} \mathrm{C}$ and $270^{\circ} \mathrm{C}$ for the alumina containing catalyst. However, it appears that there are differences in the patterns obtained for the silica containing catalyst at $230^{\circ} \mathrm{C}$ and $270^{\circ} \mathrm{C}$. At $230^{\circ} \mathrm{C}$, the fraction of ethanol and 1-propanol are essentially constant as the potassium content varies from 1 to $5 \mathrm{wt} \%$ (figure 9). Again, the amount of ethanal is small compared to that of ethanol (about 20 times more ethanol). Ethanol is present at about 4 times the weight fraction of 1-propanol; however, the weight fraction of ethanol plus ethanal is about equal to that of 1-propanol plus propanal. Propanal is a dominant oxygenate product in the aqueous phase, and the amount of propanal remains essentially constant over the potassium range of 1 to $5 \mathrm{wt} . \%$.

A number of repeat preparations of the catalyst that contains $\mathrm{Si} / \mathrm{Fe}=0.044$ and $\mathrm{K} / \mathrm{Fe}=0.71(0.5 \mathrm{wt} . \% \mathrm{~K})$ has been carried out and these have been utilized in longterm activity/selectivity studies. A representative conversion versus time curve is shown in figure 10 for a catalyst that was activated in synthesis gas for 24 hours at $270^{\circ} \mathrm{C}$ and at 14.7 psia total pressure. The catalyst exhibits long-term stability of activity, declining at a rate that is less than $1 \%$ CO conversion/week. Also included in this figure is the fraction of oxygenates (based on total oxygenates plus hydrocarbons) that are formed during the more than 2500 hours of run time. It is 
apparent that at this higher conversion level, the oxygenates are present at only about one-hundredth the fraction that they are for lower conversion levels with a similar catalyst. It therefore appears that with the silica containing catalyst, alcohol reincorporation and/or alcohol conversion (such as dehydration) occurs at high conversions to reduce the total oxygenates to a very low level. This observation with silica for the high conversion data does not appear to apply for a similar catalyst where alumina has been incorporated in place of silica. Even though the oxygenates in figure 10 are present in low concentrations, the distribution of the oxygenate compounds are essentially the same as shown in figures 8 and 9 for the lower CO conversion and higher oxygenates concentration.

The impact of the potassium content upon the carbon number distribution of the oxygenates present in the aqueous phase is illustrated in figure 11. While the carbon number $(\mathrm{N})$ is plotted versus the In $(w t . \% / N)$, this is not intended to be a typical Anderson-Schulz-Flory plot since only the oxygenates present in the aqueous phase are included in the figure. The data make it clear that, as the potassium content of the catalyst is increased, the amount of methanol declines while there is a corresponding increase in the $C_{2}$ and $C_{3}$ fractions; furthermore, the increase in the $C_{3}$ fraction is greater than for the $\mathrm{C}_{2}$ fraction.

The carbon number distribution of the oxygenate products do not depend to a measurable extent upon the content of either silica or alumina over the ranges (4 to 8 atomic $\%$ of the iron) examined in this study; this is illustrated figure 12 for the data for the alumina containing catalyst.

The water soluble $\mathrm{C}_{1}-\mathrm{C}_{4}$-oxygenates are formed in significant quantities during the Fischer-Tropsch synthesis. Thus, this water soluble oxygenate fraction represents 
about $1.5-2$ wt.\% of the hydrocarbon/oxygenate products; the alumina containing catalyst produces about $0.5 \mathrm{wt} . \%$ more oxygenates than the silica containing catalyst with a similar potassium content. In general, as the catalyst ages, the amount of oxygenates produced per unit of syngas converted gradually increases. The oxygenates production in general mirrors that of the $\mathrm{CO}$ conversion; that is, the higher the conversion the lower the oxygenates production.

The distribution of the compounds within the oxygenates is primarily determined by the amount of potassium in the catalyst but is essentially independent of the alumina or silica content. Thus, for a given alkali loading, the carbon number distribution of the catalyst is independent of the amount of either alumina or silica in the catalyst in the 4 to $8 w t . \%$ loading.

As the alkali loading of the catalyst is increased the normal alcohol fractions decrease. The oxygenate that increases most dramatically with an increase in potassium loading is the aldehyde class of compounds. The increase in ethanal is much less, relative to ethanol, than the increase in propanal relative to 1-propanol. At least some fraction of the ethanal is converted to products consistent with aldol condensation reactions to produce higher carbon number compounds that are not soluble in the aqueous phase. The ethanol-ethanal is essentially in equilibrium during synthesis using a C-73 catalyst manufactured by United Catalyst, Inc. (L.-M. Tau, H. A. Dabbagh and B. H. Dabbagh, Energy \& Fuels, 5 (1991) 174); thus, the same ethanol/ethanal ratio was obtained whether ethanol or ethanal was added to the syngas feed. This was not the case in the present study. For the catalyst containing 3 to $5 \mathrm{wt} . \%$ potassium, the propanal/1-propanol ratio was about 4 whereas for the catalyst with 0.5 wt.\% potassium this ratio was 0.1 or less. This observation implies 
that for the high loadings of potassium, the inability of the catalyst to establish this equilibrium is due to the enhancement of the desorption of the aldehyde and/or $\mathrm{CO}$ inhibition retards readsorption of the aldehyde. Furthermore, at least for the high potassium loadings, the formation of the high concentration of aldehyde implies that the aldehyde, and not the primary normal alcohol, is a primary product of the FischerTropsch synthesis. It seems likely that the direct formation of the aldehyde occurs by a reaction pathway that competes with the Fischer-Tropsch synthesis and which is similar to or is a hydrocarbonylation reaction.

In summary, it appears that a Fischer-Tropsch plant that has the objective of developing a chemicals component based upon oxygenates would want to use alumina as the structural promoter. Furthermore, the operator could have some control over the amount and distribution of the oxygenate products by controlling the level of potassium that is present in the catalyst.

\section{A.3. Prepare Catalysts that can be Used to Quantify the Role of K on Product}

\section{Selectivity for both High- and Low-Alpha Catalysts}

Low-alpha catalyst work has been successfully completed. Work is in progress on supported catalysts to increase the hydrocarbon production by increasing the amount of alkali.

\section{A.4. Complete the Optimization of Two Best Low-Alpha, Iron-Based Catalysts}

\section{Developed During the Previous Contract}

Completed.

\section{A.5. Schedule of Activities for Next Quarter}

- Begin optimization of the robust alumina supported catalyst to increase conversion, selectivity and production. 


\section{B.0. - Task 2.0. Definition of Preferred Pretreatment for Both Low- and High-}

\section{Alpha Catalysts}

The goals of this task are to define the preferred treatment, to define the role of $\mathrm{Cu}$ and $\mathrm{K}$ during the pretreatment on activity and selectivity and to define the chemical and physical changes which occur during the preferred pretreatment. The subtasks address each of these goals.

B.1. Role of $\mathrm{Cu}$ in the Activation of Precipitated Low- and High-Alpha, Iron Based Fischer-Tropsch Catalysts

This task has been successfully completed for both high and low alpha catalysts.

\section{B.2. Determine the Effect of $\mathrm{K}$ Content on Activation Procedures and}

Determinate if the Method of Addition has any Effect on Catalyst Activity and Life.

The work on the method of addition has been completed.

\section{B.3. Physical and Chemical Changes that Occur During Pretreatment and Use}

No scheduled or further activity to report.

\section{B.4. Effect of Carbon Deposition}

No scheduled or further activity to report.

\section{B.5. Schedule of Activities for Next Quarter}

Continue to determine effectiveness of $\mathrm{Ba}$ and $\mathrm{Zn}$ as promoters.

\section{C.0. - Task 3.0. Catalyst Structure and Characterization}

The goal of this task is to provide basic analyses (surface area, XRD) of all catalyst prepared and to provide additional techniques as required (Mössbauer, SEM, 
XPS, etc.) to answer specific questions or to provide basic required characterization data for the catalysts.

\section{C.1. Schedule of Activities for Next Quarter}

Continue to provide the characterization data as required.

\section{D.0. - Task 4.0. Catalyst Testing}

The goals of this task are to operate the eight CSTR reactors, measure catalyst performance, determine the stable phases that exist during synthesis at low and high conversions and to determine the rates of interconversion of iron oxide and carbide.

\section{D.1. Verify the Quality of Data Obtained from the CSTRS.}

This task is now successfully completed.

\section{D.2. Measure Catalyst Performance}

The run using a high alpha catalyst to evaluate the modification of the catalyst/wax separation has been successfully running for 700 hours. It appears the new modification for catalyst settling and return to reactor is working well; however, it will take approximately an additional month of continuous operation to verify this result.

D.3. Determine Stable Phases that Exist During Synthesis at High and Low CO

\section{Conversion Levels}

We have completed runs using an unpromoted $\mathrm{Fe}$ and a $\mathrm{K}$ promoted $\mathrm{Fe}$ catalyst which will provide samples for the analysis of the stable phases.

D.4. Obtain Data on Rates Involved in the Interconversion of Iron Oxide and

\section{Carbide}

No scheduled or additional activity to report. 


\section{D.5. Schedule of Activities for Next Quarter}

- Continue the evaluation of the wax/catalyst separation.

- Continue to make additional supported Fe catalysts and test their activity, selectivity and productivity rate.

- Evaluate the data from the high temperature gas chromatograph (up to $\sim \mathrm{C}_{100}$ ) for internal consistency to determine if a catalyst produces a 1 or 2 alpha product distribution. 


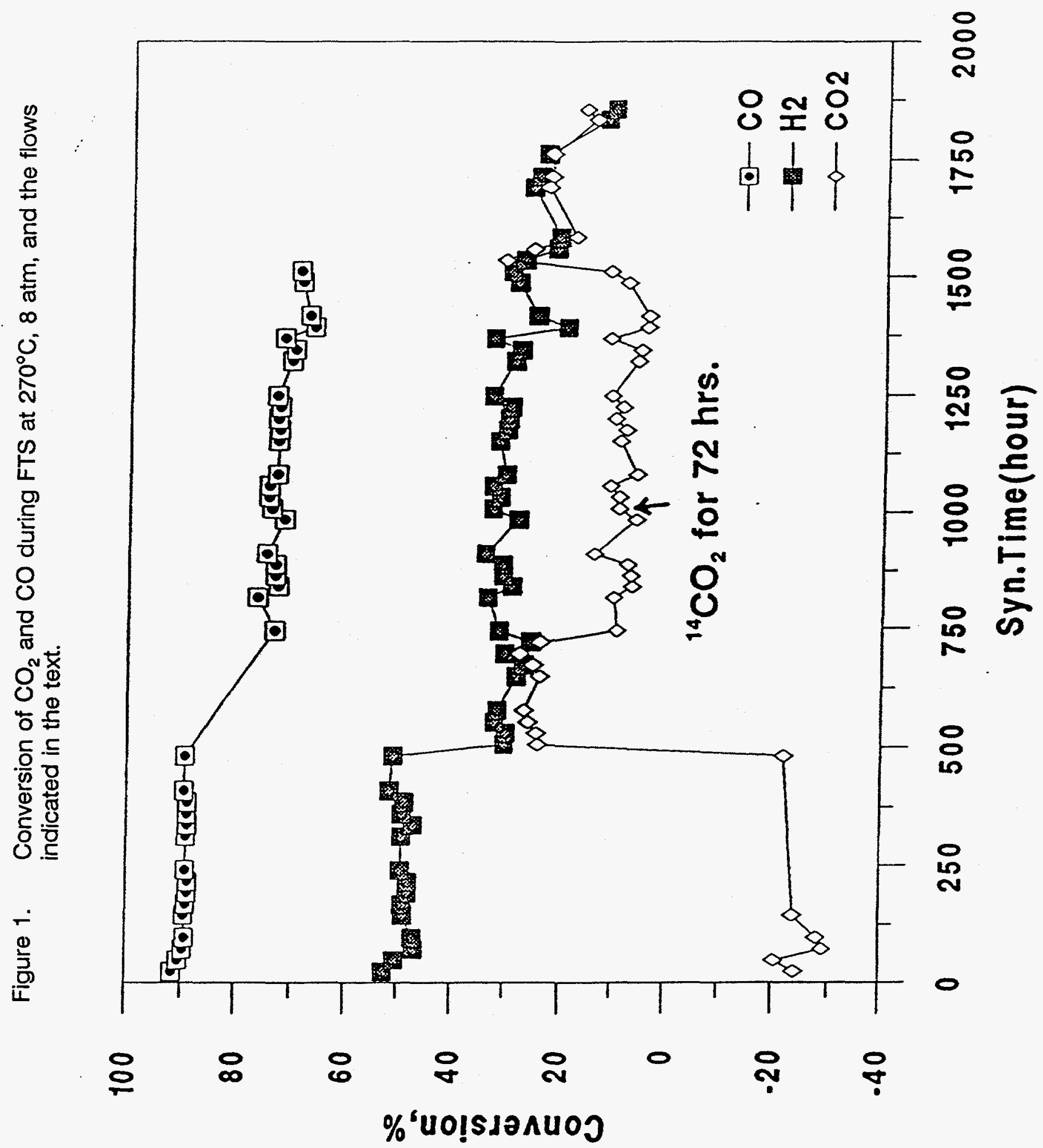



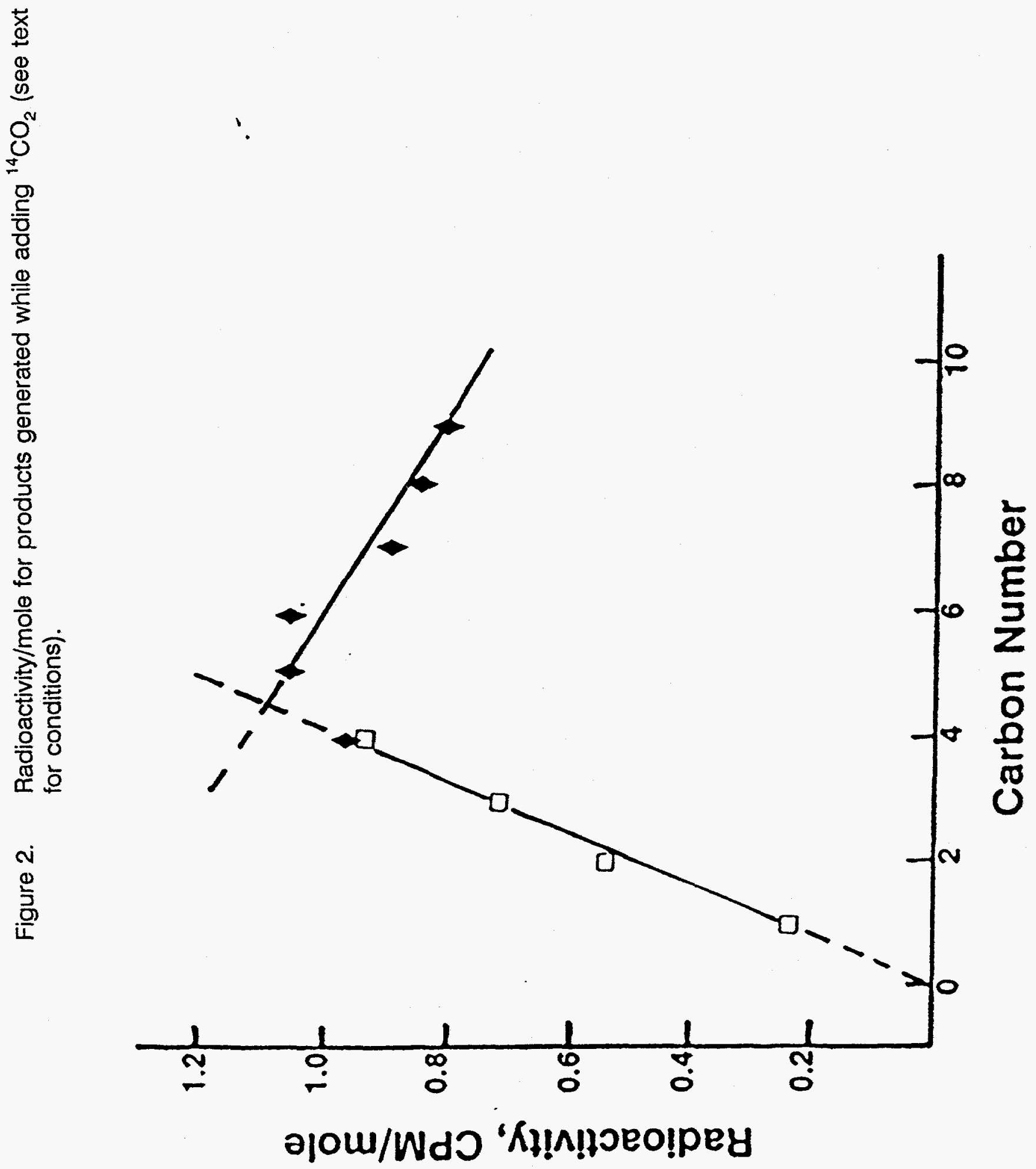
Figure 3. Composite figure showing relative radioactivity for the lower carbon number compounds (O); the measured values for the higher carbon number compounds (O), and the values for the higher carbon number compounds $(\diamond)$ after correcting for reactor accumulation effects.

\section{$\log (C P M / \%$ MMole)}

Carbon-14/Mole, Relatlve

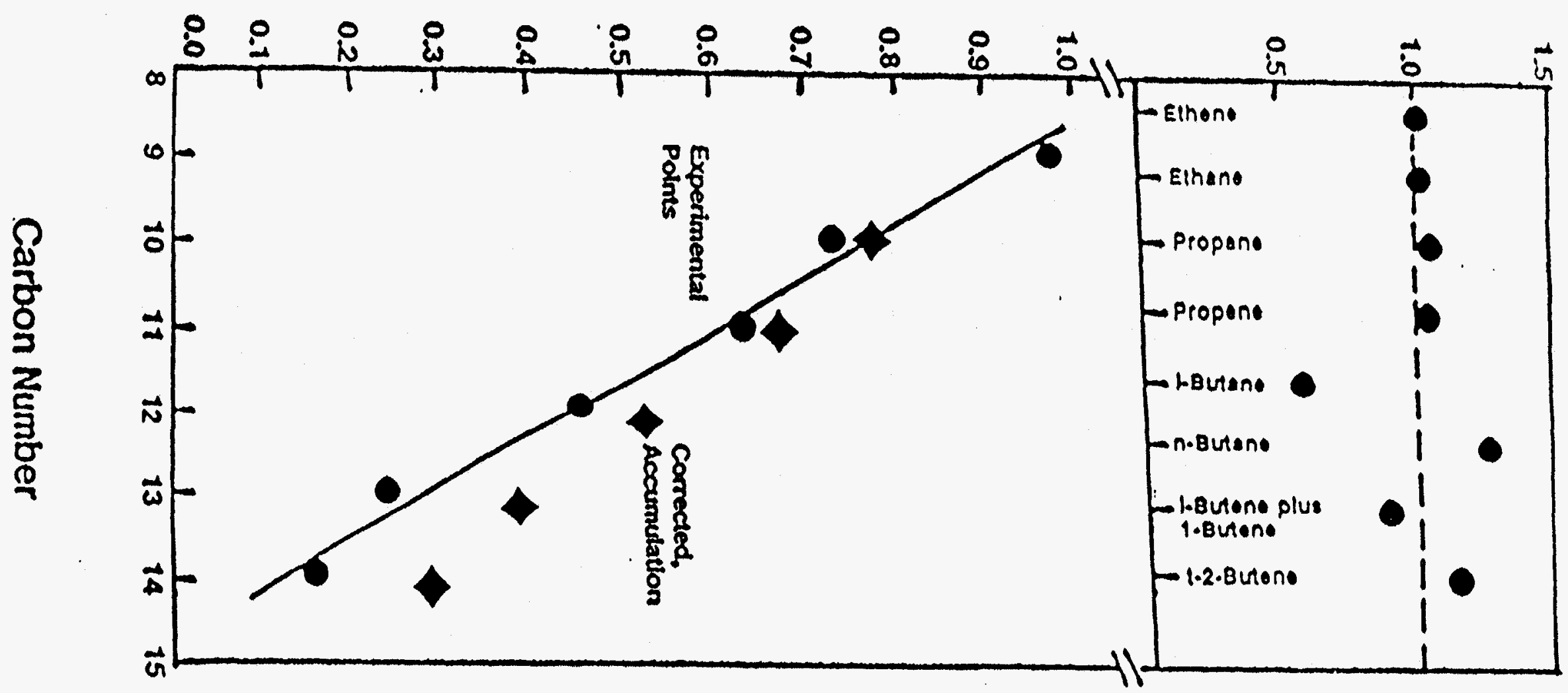


Figure 4. The percentage of oxygenates in the hydrocarbonate plus oxygenate fraction from the conversion of synthesis gas $\left(\mathrm{H}_{2} / \mathrm{CO}=0.7 ; \mathrm{T}=230\right.$ or $270^{\circ} \mathrm{C} ; \mathrm{P}=170 \mathrm{psig} ; 3.1 \mathrm{NL} / \mathrm{hr}$.-g.Fe) with iron catalysts containing silica or alumina ( $\mathrm{Si}$ or $\mathrm{Al} / \mathrm{Fe}=0.044$ ) with varying amounts of potassium (o, alumina at $230^{\circ} \mathrm{C} ; \bullet$, alumina at $270^{\circ} \mathrm{C} ; \square$, silica at $230^{\circ} \mathrm{C}$; and $\square$, silica at $270^{\circ}$ ).

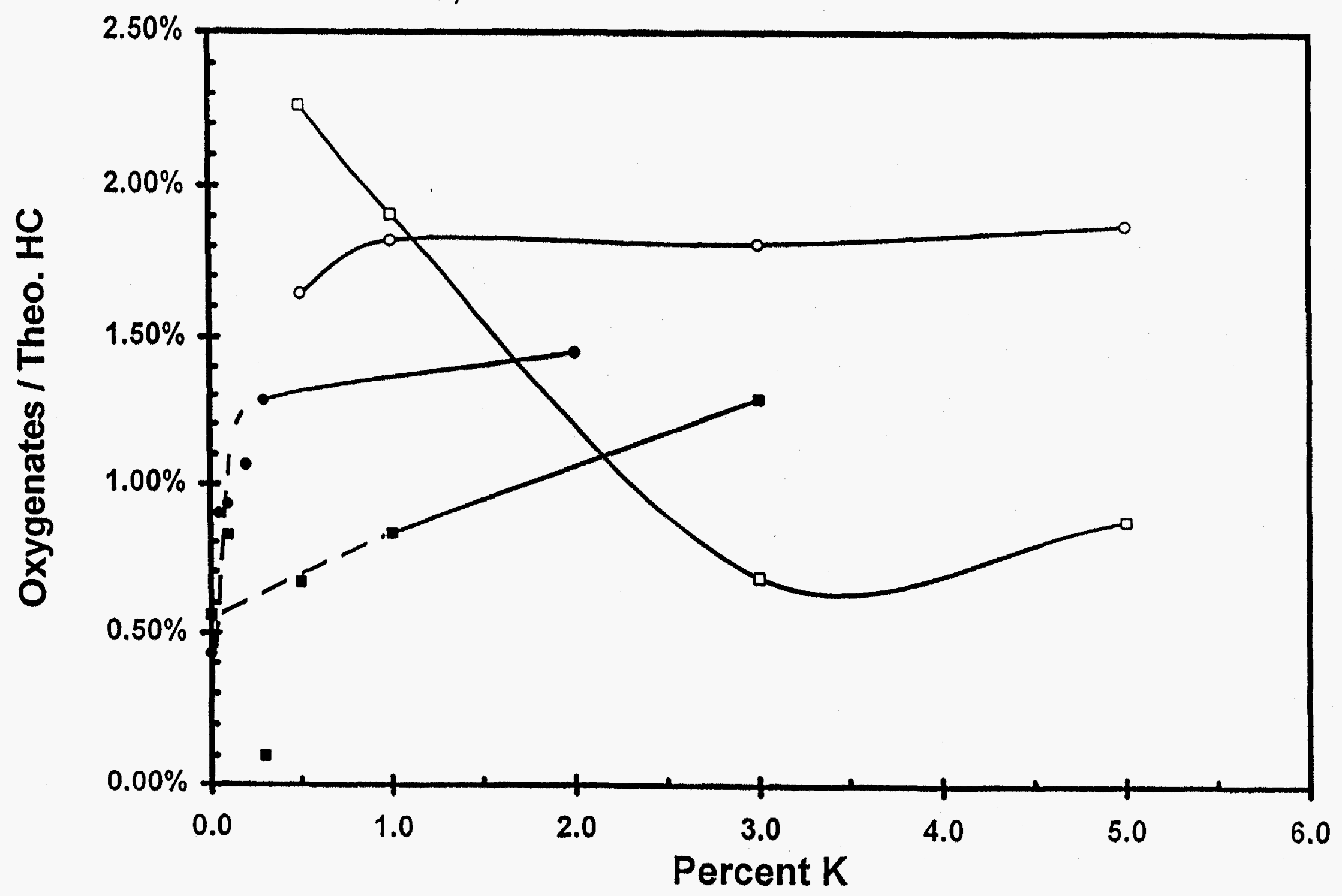




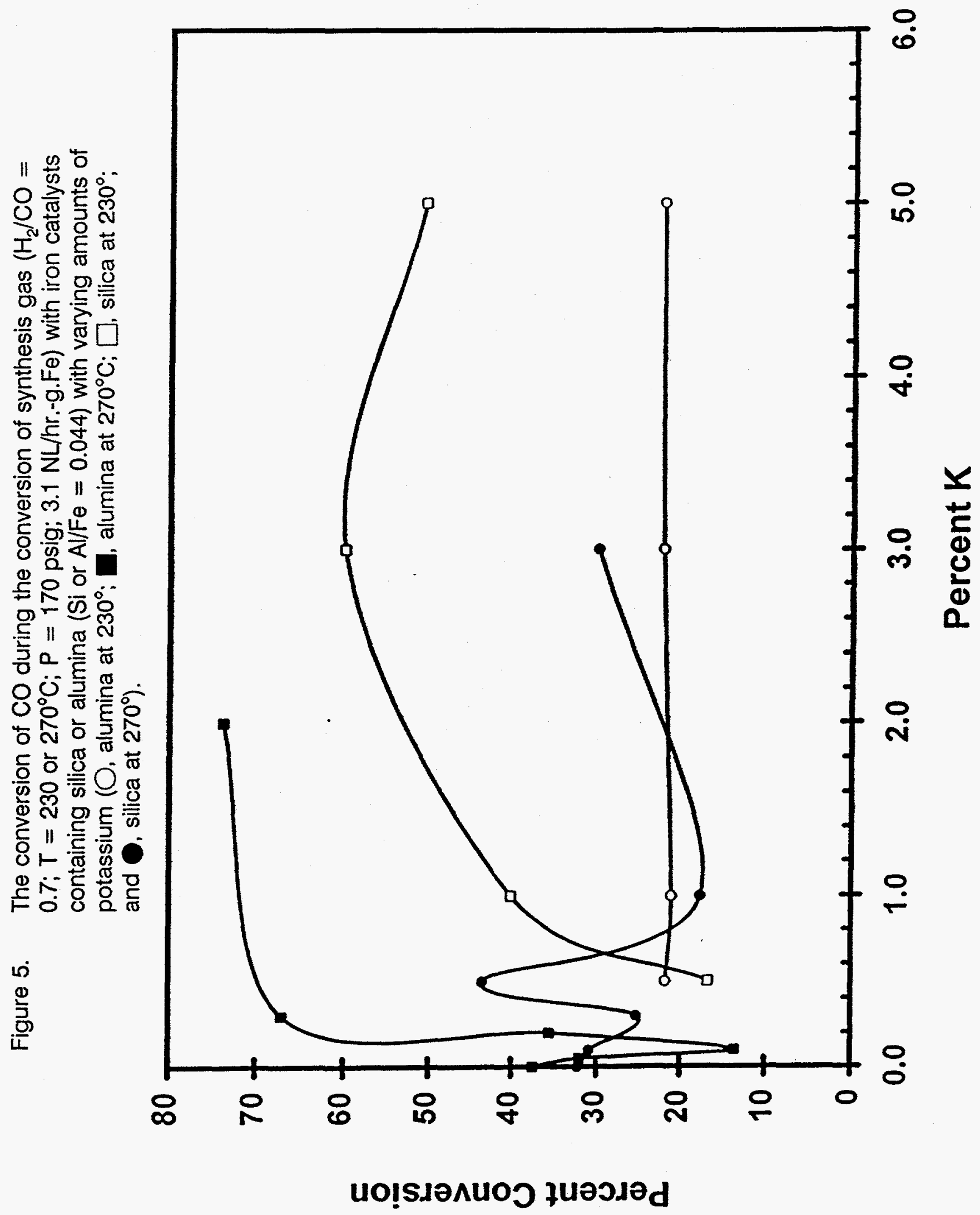


Figure 6. The weight percent of oxygenate compounds in the aqueous phase formed during the conversion of synthesis gas with an alumina $(\mathrm{Al} / \mathrm{Fe}=$ 0.044 ) containing iron catalyst and 0.5 wt.\% potassium $\left(\mathrm{H}_{2} / \mathrm{CO}=0.7 ; \mathrm{T}\right.$ $=230$ or $270^{\circ} \mathrm{C} ; \mathrm{P}=170 \mathrm{psig} ; 3.1 \mathrm{NL} / \mathrm{hr} . \mathrm{g}$.Fe;, methanol; $\mathbf{\square}$, ethanol; $\boldsymbol{\Delta}$, ethanal; $x$, acetone; $*$, 2-propanol; 1 -propanol; and +, 1 butanol).

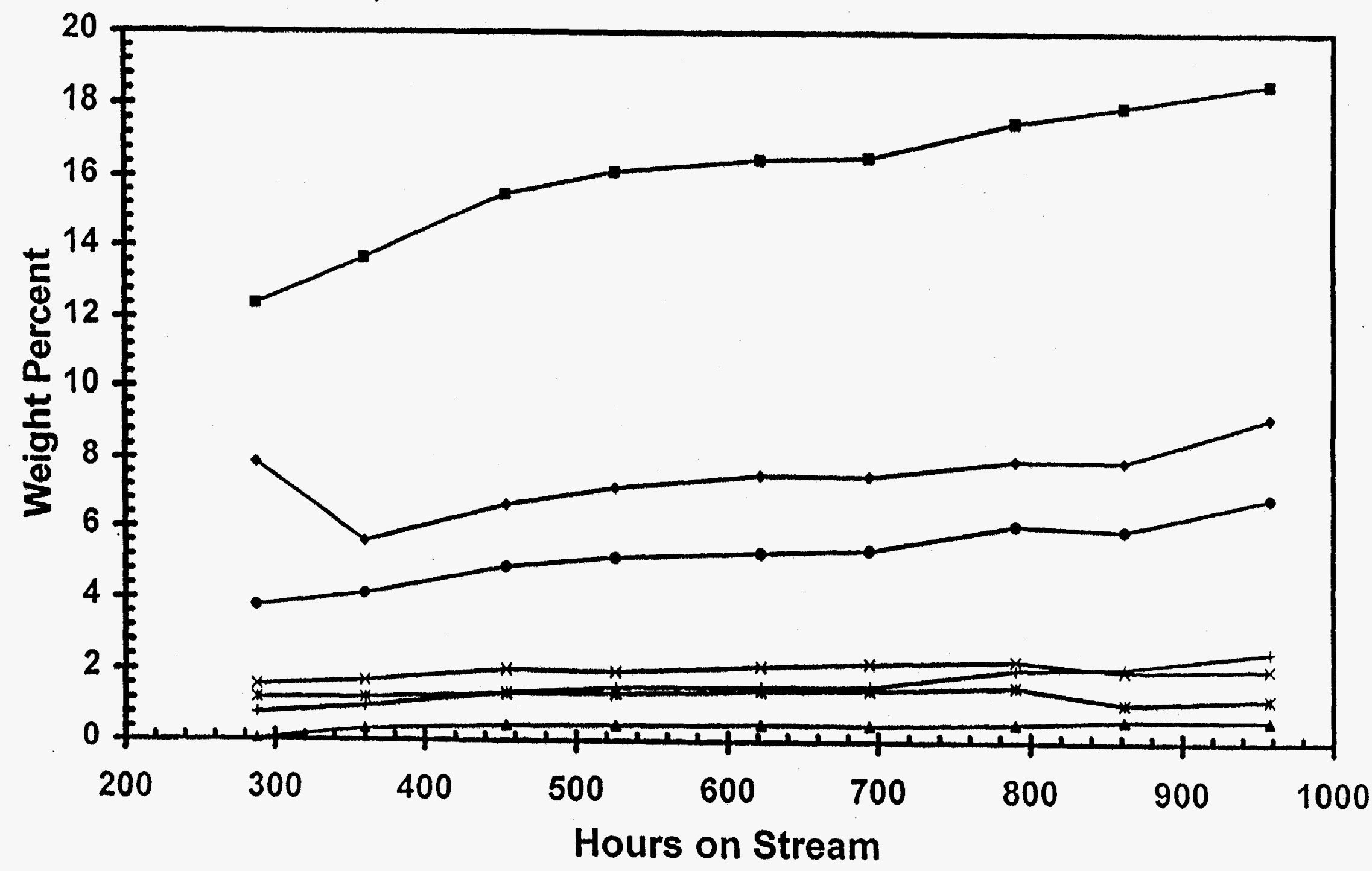


Figure 7. The weight percent of oxygenate compounds in the aqueous phase formed during the conversion of synthesis gas with an silica ( $\mathrm{Si} / \mathrm{Fe}=$ $0.044)$ containing iron catalyst and $0.5 \mathrm{wt} \%$ potassium $\left(\mathrm{H}_{2} / \mathrm{CO}=0.7 ; \mathrm{T}\right.$ $=230$ or $270^{\circ} \mathrm{C} ; \mathrm{P}=170 \mathrm{psig} ; 3.1 \mathrm{NL} / \mathrm{hr}$.-g.Fe; methanol; $\mathbf{\square}$, ethanol; $\boldsymbol{\Lambda}$, ethanal; $x$, acetone; *, 2-propanol; 0 , 1-propanol; and +, 1-

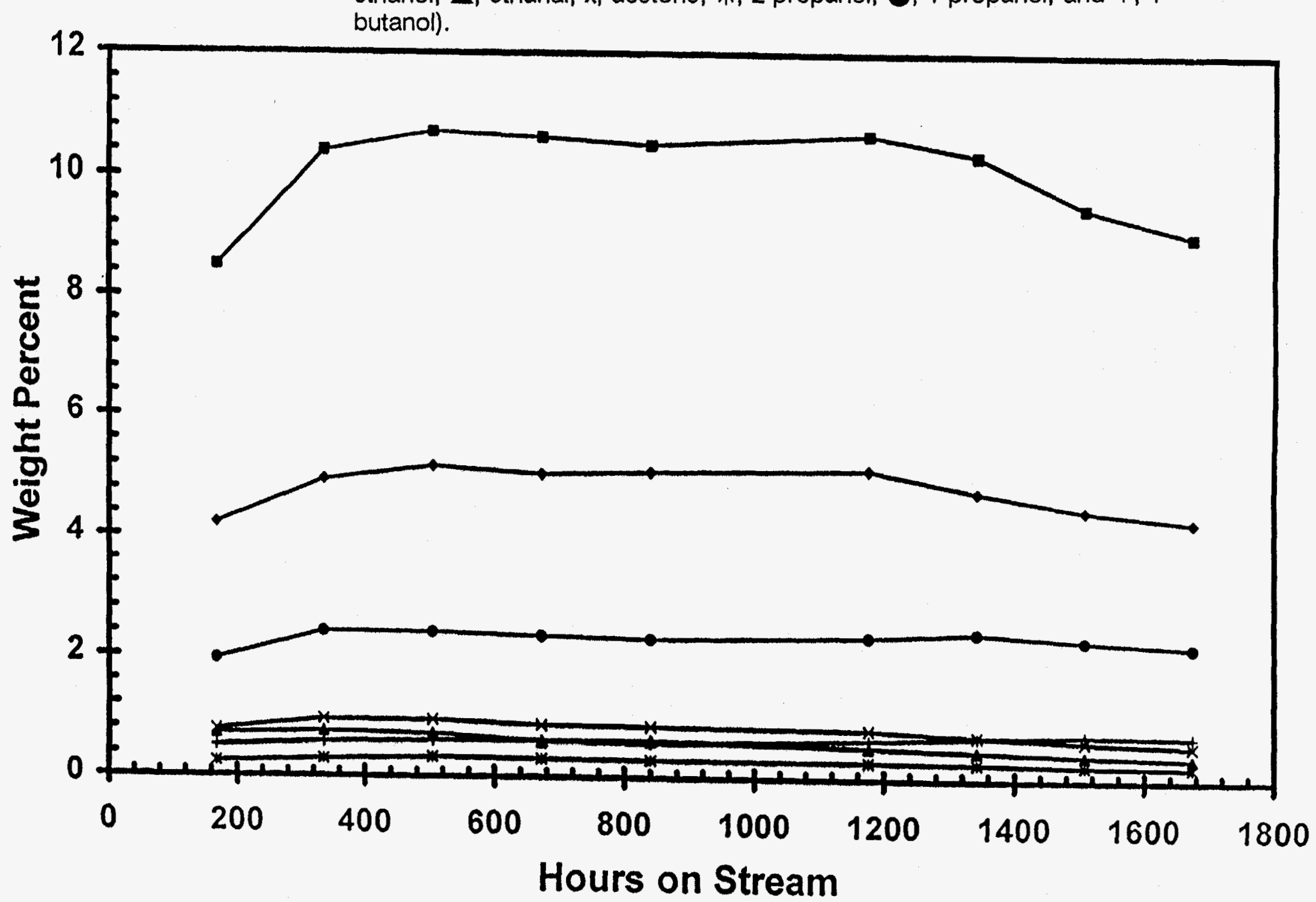


Figure 8. The percentage of the oxygenate fraction made up by individual compounds (O. methanol; $\boldsymbol{\Delta}$, ethanol; $x$, ethanal; $\boldsymbol{\square}$, 1-propanol; and $\downarrow$, propanal) from the conversion of syngas with an silica $(\mathrm{Si} / \mathrm{Fe}=0.044)$ containing iron catalyst and 0.5 wt.\% potassium $\left(\mathrm{H}_{2} / \mathrm{CO}=0.7 ; T=\right.$

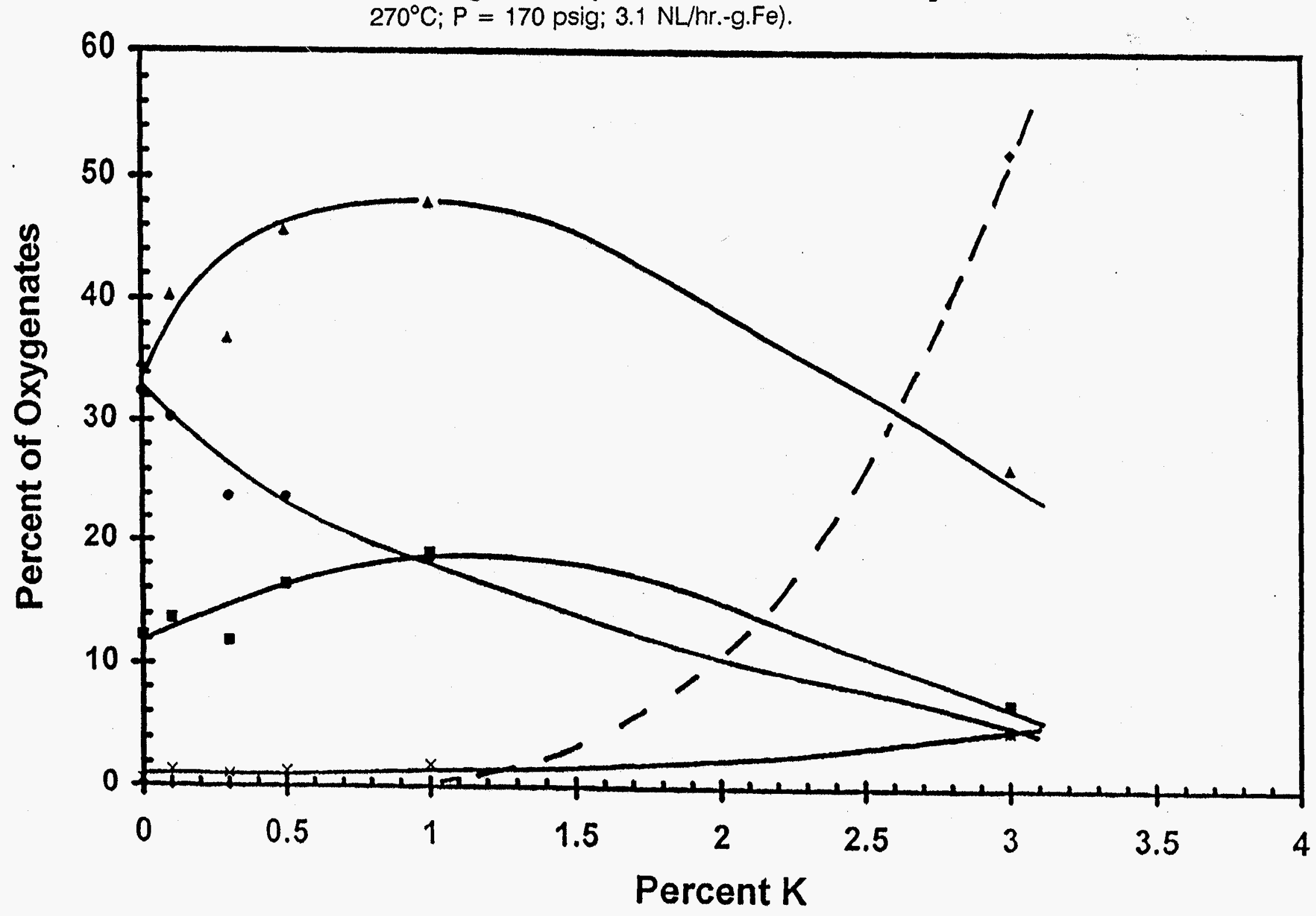


Figure 9. The percentage of the oxygenate fraction made up by individual compounds ( , methanol; $\boldsymbol{\Delta}$, ethanol; $x$, ethanal; 1 , 1-propanol; and propanal) from the conversion of syngas with an silica $(\mathrm{Si} / \mathrm{Fe}=0.044)$ containing iron catalyst and $0.5 \mathrm{wt}$ \% potassium $\left(\mathrm{H}_{2} / \mathrm{CO}=0.7 ; \mathrm{T}=\right.$ $230^{\circ} \mathrm{C} ; \mathrm{P}=170 \mathrm{psig} ; 3.1 \mathrm{NL} / \mathrm{hr} .-\mathrm{g} . \mathrm{Fe}$ ).

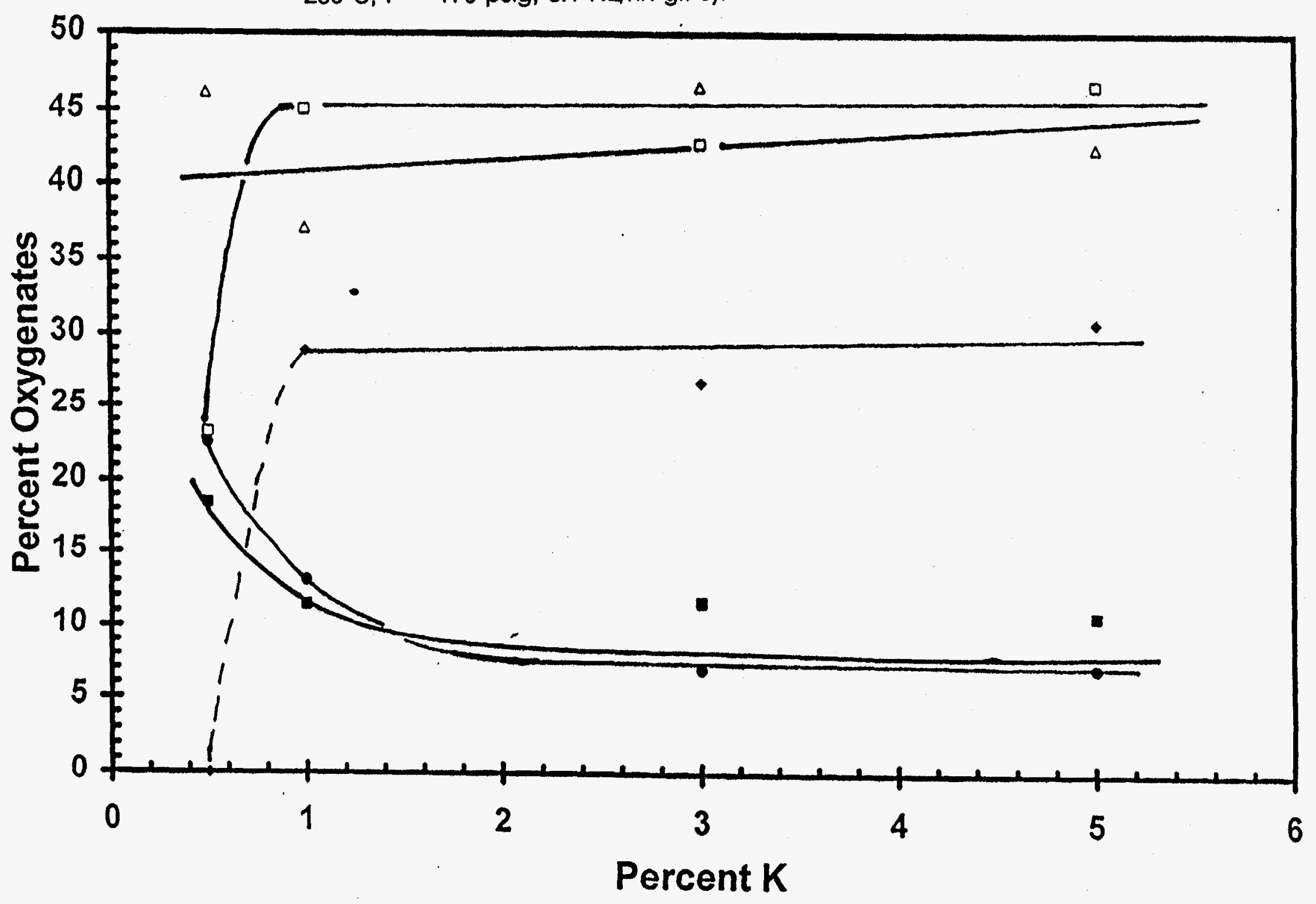


Figure 10. The conversion and oxygenates production during long term testing of a precipitated iron catalyst containing silica $(\mathrm{Si} / \mathrm{Fe}=0.044)$ and potassium (0.5 wt.\%).

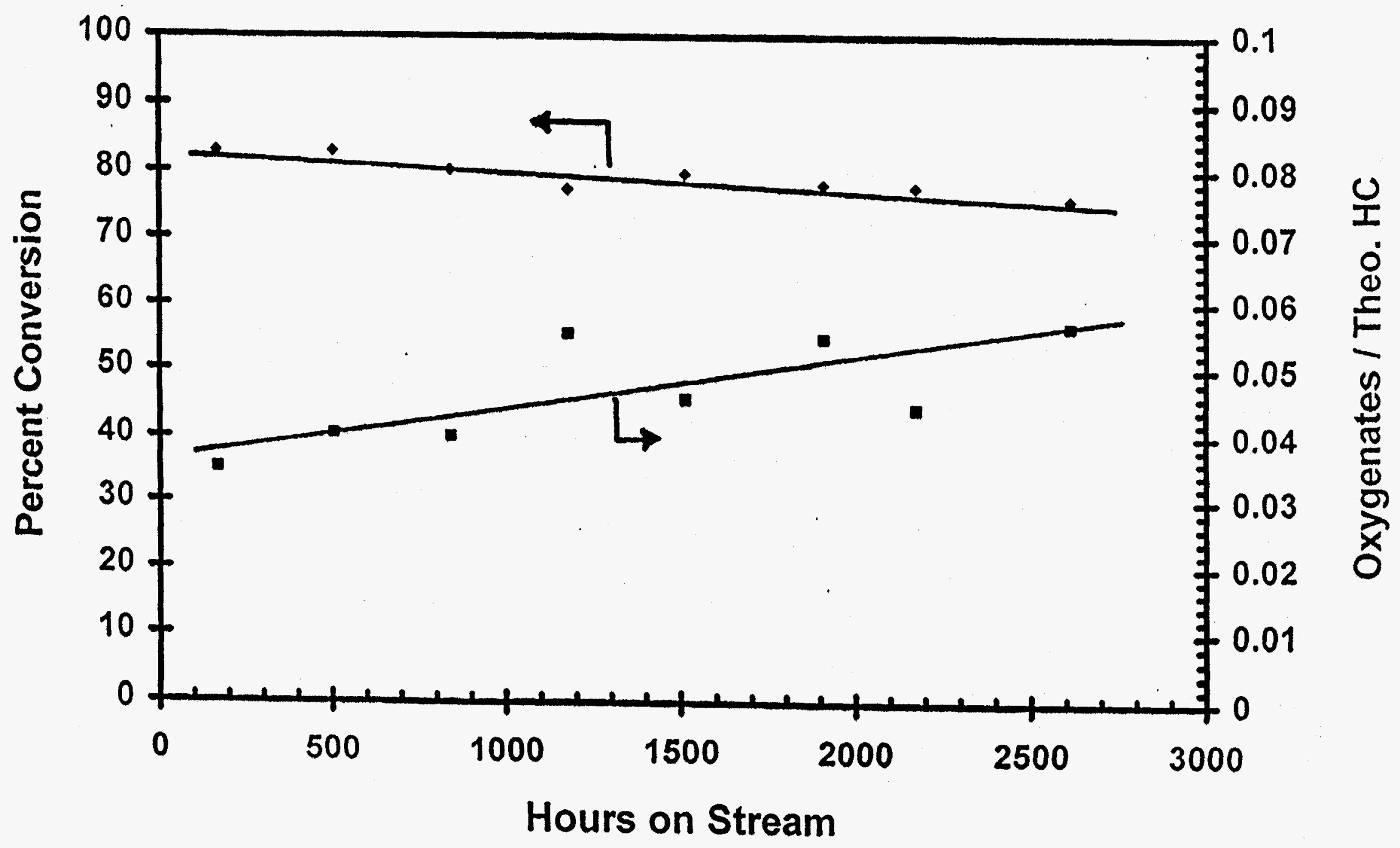


Figure 11. The In $[(W t . \% N) / N]$ versus the carbon number, $N$, of the oxygenates formed from the conversion of syngas with an alumina $(\mathrm{Al} / \mathrm{Fe}=0.044)$ containing iron catalyst and various wt.\% potassium indicated by numbers with each curve $\left(\mathrm{H}_{2} / \mathrm{CO}=0.7 ; \mathrm{T}=270^{\circ} \mathrm{C} ; \mathrm{P}=170\right.$ psig; 3.1 NL/hr.-g.Fe.

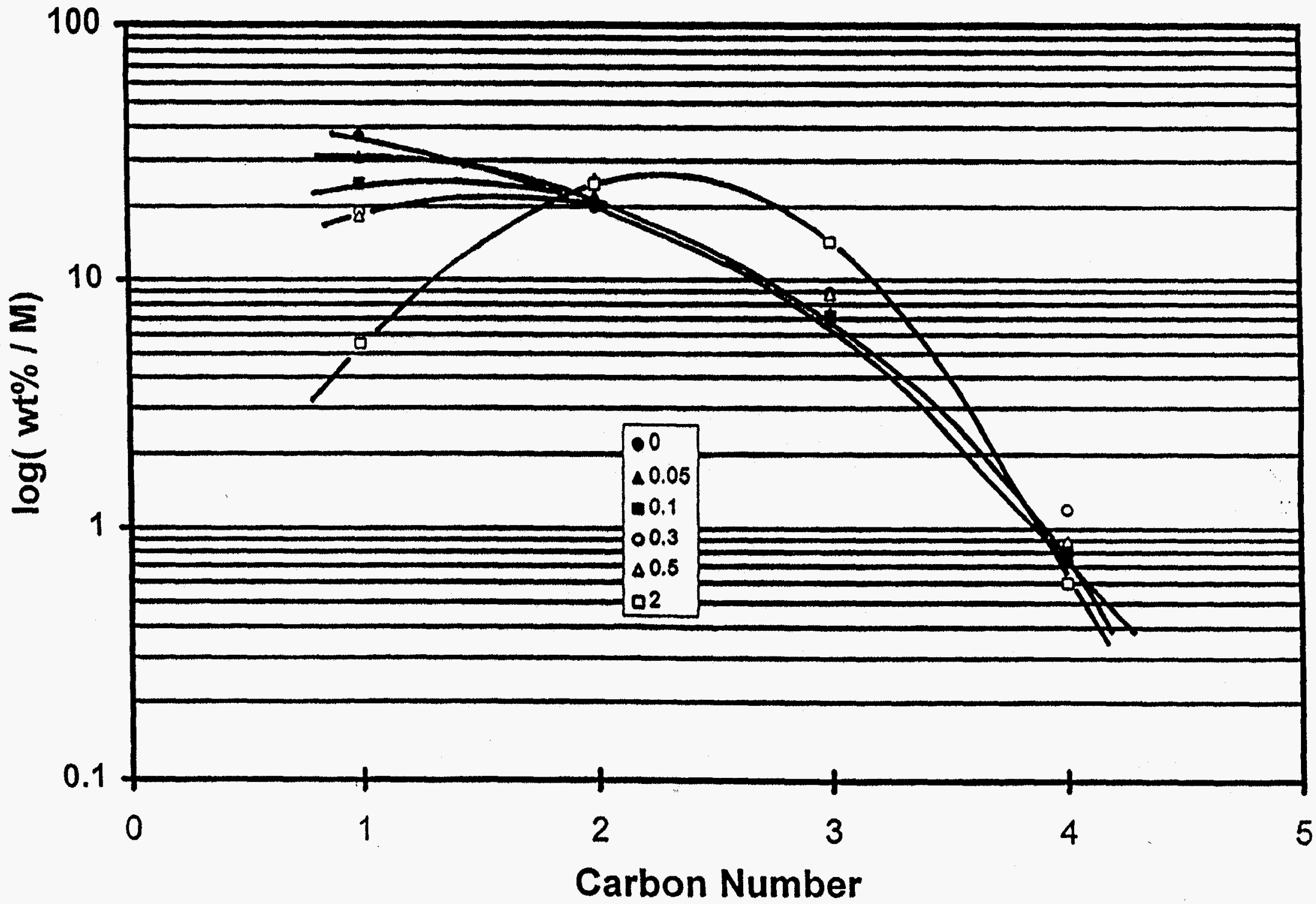


Figure 12. The In $[(\mathrm{Wt} . \% \mathrm{~N}) / \mathrm{N}]$ versus the carbon number, $\mathrm{N}$, of the oxygenates formed from the conversion of syngas with an alumina $(\boldsymbol{A}, \mathrm{Al} / \mathrm{Fe}=$ $0.044 ; \mathrm{Al} / \mathrm{Fe}=0.06$; and $\square, \mathrm{Al} / \mathrm{Fe}=0.08$ ) containing iron catalyst with 0.5 wt.\% potassium $\left(\mathrm{H}_{2} / \mathrm{CO}=0.7 ; \mathrm{T}=270^{\circ} \mathrm{C} ; \mathrm{P}=170\right.$ psig; 3.1 NL/hr.-g.Fe.

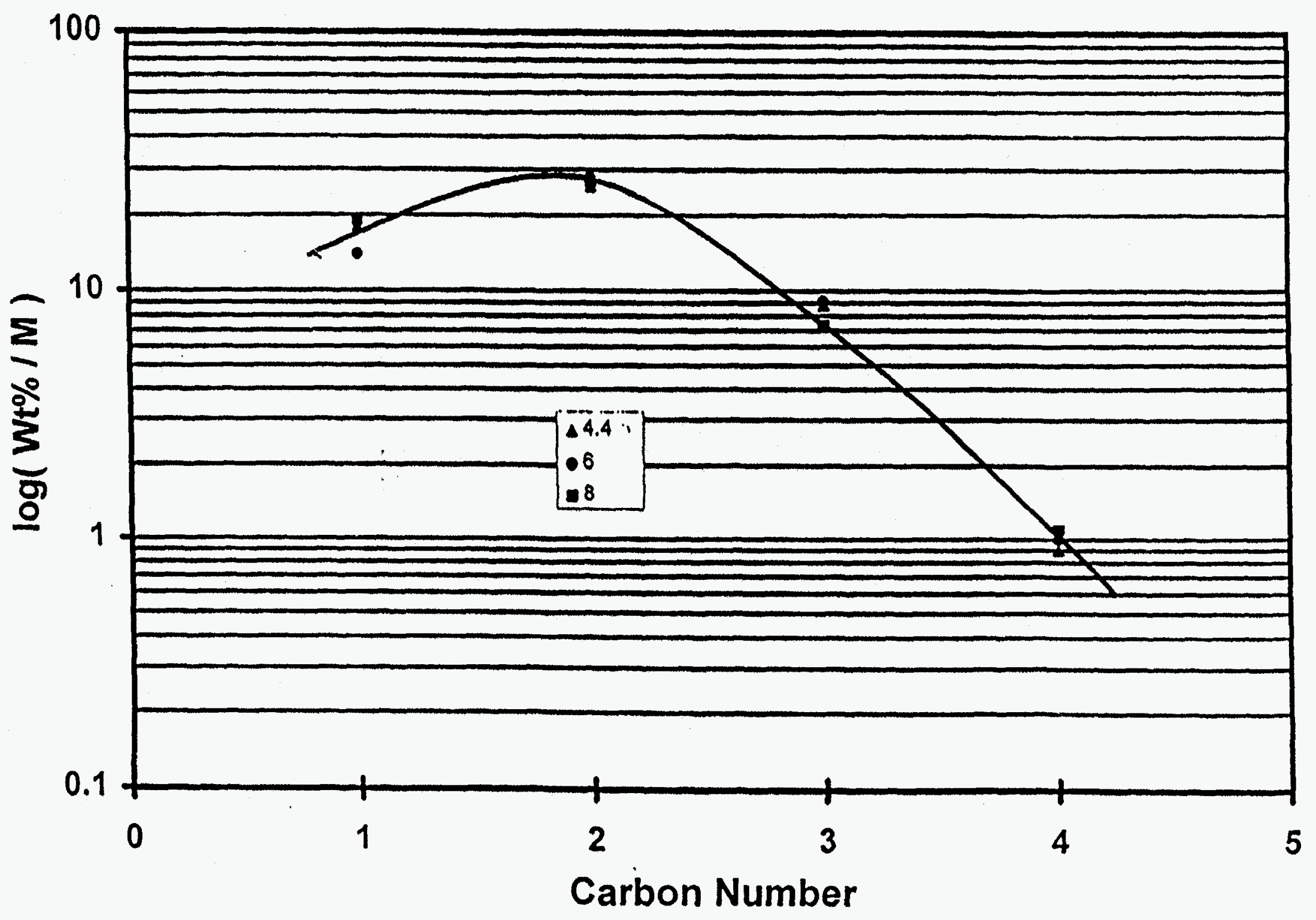

